K. Vogiatzis, Int. J. Sus. Dev. Plann. Vol. 8, No. 2 (2013) 173-185

\title{
ENVIRONMENTAL NOISE AND VIBRATION MONITORING AND ASSESSMENT OF MAJOR ROAD TRANSPORTATION NETWORKS: THE CASE OF ELEFSINA (ATHENS) - KORINTHOS MOTORWAY (2008-2011)
}

\author{
KONSTANTINOS VOGIATZIS \\ University of Thessaly, Department of Civil Engineer, Volos Greece.
}

\begin{abstract}
Environmental noise and vibration annoyance - especially from road transportation networks - is widely accepted as an end-point of environmental assessment that can be taken as a basis for evaluating the impact and annoyance caused to the exposed population. This paper presents the results of a comprehensive monitoring program for environmental noise and vibration from ELEFSINA (ATHENS) - KORINTHOS (an upgraded three-lane motorway crossing the famous Korinthos canal with a total length of $63 \mathrm{~km}$ ), as well as the resulting appropriate noise action plan, including adequate mitigation measures for environmental road noise abatement. In the framework of this monitoring program, 40 locations were selected for airborne noise monitoring (various indices as $\mathrm{L}_{\mathrm{A}}$ eq $(08: 00-20: 00), \mathrm{L}_{\mathrm{A}} 10(18 \mathrm{~h}), \mathrm{L}_{\text {den }}, \mathrm{L}_{\text {night }}$ ) and 24 locations for vibration (ground borne noise both in $\mathrm{dB}(\mathrm{A})$ and peak vibration velocity $-\mathrm{PPV}$ in $\mathrm{mm} / \mathrm{s}$ ) monitoring covering all sensitive uses as per residential buildings, educational uses, churches, etc. A full assessment of all measured results and the noise mapping assessment was also executed. This assessment aimed at the implementation of appropriate noise barriers with synthetic axes, upon which the total aesthetical and acoustic adaptation was based to fulfill the need for adequate noise protection criteria and full aesthetic consistency of the final outcome with the builtup surrounding landscape. In conclusion, some $9,000 \mathrm{~m}^{2}$ of semi-transparent noise barriers are already under construction. Environmental noise and vibration monitoring programs are proven to be a crucial parameter in sustainability assessments of inter- and semi-urban road networks.

Keywords: environmental noise, environmental vibration, noise barriers, noise limits, noise protection, road traffic noise, road traffic vibration, vibration limits.
\end{abstract}

\section{INTRODUCTION - THE PROJECT}

OLYMPIA ODOS S.A. is a consortium selected by the Greek Ministry of Public Works to design, finance, construct, operate, and maintain the Olympia Odos motorway for a period of 30 years, starting from 2008. Construction activities and relevant works are focused on the construction of new motorway sections and the full upgrade of the existing ones, at a total length of $284 \mathrm{~km}$, that is:

- the $120 \mathrm{~km}$ of the Korinthos-Patra section, with two traffic lanes along with an emergency lane per direction and a central reserve.

- the $164 \mathrm{~km}$ of the Patra-Pyrgos and Alfeios-Tsakona sections, with two traffic lanes along with an emergency lane per direction and a central reserve for the first section and two traffic lanes per direction with a central reserve for the second section, and the upgrading of the existing motorway sections of a total length of $82 \mathrm{~km}$ (e.g. www.olympiaodos.gr [1]) that is:

(a) the $63 \mathrm{~km}$ of the Elefsina (Athens)-Korinthos section, which is an existing three-lane motorway crossing the famous Korinthos canal (connecting the Gulf of Corinth with the Saronic Gulf in the Aegean Sea and cutting through the narrow Isthmus of Corinth separating the Peloponnesian peninsula from the Greek mainland, finally completed on 25 July 1893 after 11 years' work (see Figs. 1 and 2) and

(b) the $\mathbf{1 8} \mathbf{~ k m}$ of the Patra Bypass section, which is an existing two-lane motorway. 


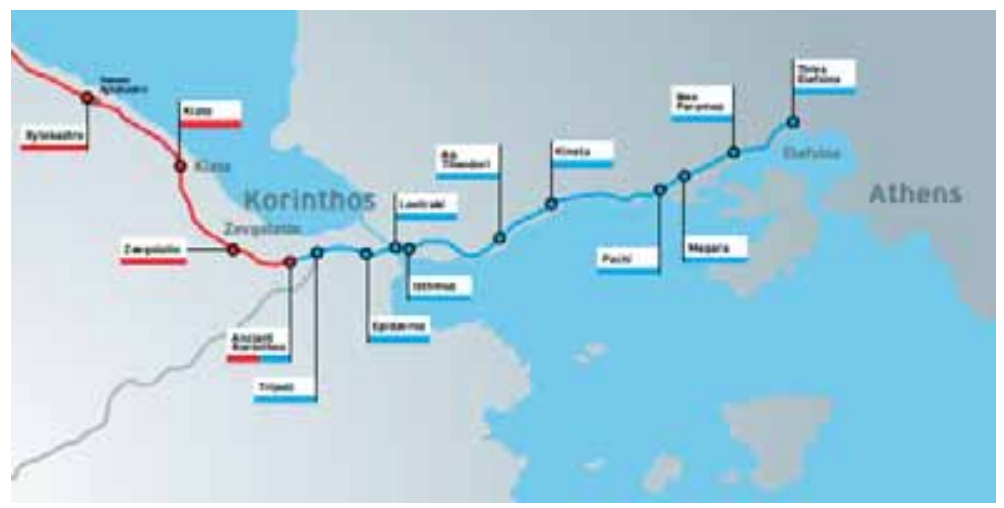

Figure 1: Elefsina (Athens)-Korinthos Motorway - General layout.

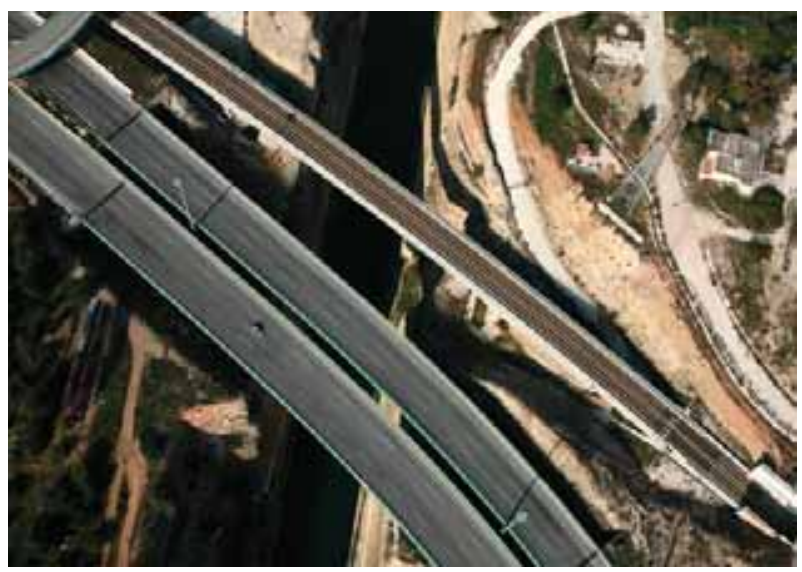

Figure 2: Elefsina (Athens)-Korinthos Motorway over Korinthos canal.

While designing and organizing the first phase of this major project, especially the Elefsina (Athens)-Korinthos section, all parameters to ensure minimal environmental effects were taken into account. In particular, regarding environmental noise and vibration during operation, the new motorway will allow minimization of environmental effects in terms of environmental road noise and vibration, ensuring an increased environmental sustainability (e.g. www.olympiaodos.gr [1]).

The annual average daily traffic volume of the motorway is measured for year 2006 at a total of 35,136 vehicles (Private cars: 30,655, Heavy vehicles: 4,481) and estimated for year 2016 at 44,313 vehicles (Private cars: 38,313, Heavy vehicles: 6,000).

\section{ENVIRONMENTAL ROAD TRAFFIC NOISE AND VIBRATION MONTORING}

\subsection{Environmental road traffic noise monitoring program}

Environmental noise is an important environmental factor and one which is responsible for the degradation of the urban environment and quality of life especially in countries where climatic conditions favor outdoor activities and night life. Environmental noise annoyance, especially from road 
transportation, is widely accepted as an endpoint of environmental noise that can be taken as a basis for evaluating the impact of noise on the exposed population. People annoyed by noise may experience a variety of negative responses, such as anger, disappointment, dissatisfaction, withdrawal, helplessness, depression, anxiety, distraction, agitation, or exhaustion. (e.g. WHO-JRC 2011, [2]).

In Greece, the Joint Ministerial Decision 17252/19.6.1992, Official Journal of Hellenic Republic 395/B/92 on the 'Determination of indicators and maximum permitted noise limits that come from the movement of on-road and other transportation works' (e.g. JMD 17252/19.6.1992, [3]) defines the categories of transportation works for which enactment of maximum environmental road transportation noise limit is required and also determines the indicator of traffic noise for the quantitative and qualitative estimation of noise that comes from transportation works. The maximum noise limits are set as follows: (a) $67 \mathrm{~dB}(\mathrm{~A})$ for the noise index $\mathrm{L}_{\mathrm{A}}$ eq $(8-20 \mathrm{~h}$ ) and (b) $70 \mathrm{~dB}(\mathrm{~A})$ for the noise index $\mathrm{L}_{\mathrm{A}} 10(18 \mathrm{~h})$.

However, special cases, such as schools, hospitals, theaters, etc., for which special acoustic protection is required, are assessed by introducing limits for the above indices, of 5 or even $10 \mathrm{~dB}(\mathrm{~A})$ less. Furthermore, in the Greek environmental noise legal framework, the Directive 2002/49/EC (e.g. Directive 2002/49, [4]) is also in force. This EU Directive aims to define a common approach intended to avoid, prevent, or reduce on a prioritized basis the harmful effects (including annoyance) occurring due to exposure to environmental noise, an assessment much needed indeed in major Greek urban centers (e.g. Vogiatzis K, [5]). To that end, the following actions shall be implemented progressively:

- Determination of exposure to environmental noise, through noise mapping using methods of assessment common to the Member States;

- ensuring that information on environmental noise and its effects become available to the public;

- adoption of action plans by the Member States, based on noise-mapping results, with a view to preventing and reducing environmental noise where necessary, and in particular where exposure levels can induce harmful effects on human health and also to preserving environmental noise quality where it is good.

The scope of this Directive shall apply to environmental noise to which humans are exposed particularly in built-up areas, in public parks, or other quiet area, near schools, hospitals, and other noise sensitive buildings or places and in quiet areas in open country. Member States shall apply the noise indicators $\mathrm{L}_{\text {den }}$ and $\mathrm{L}_{\text {night }}$ that shall be determined by means of the assessment methods.

The definition of the $\mathrm{L}_{\text {den }}$ level (day-evening-night) is defined by the following formula:

$$
L_{d e n}=10 \lg \frac{1}{24}\left(12 * 10^{\frac{L_{d a y}}{10}}+4 * 10^{\frac{L_{\text {evening }}+5}{10}}+8 * 10^{\frac{L_{\text {might }}+10}{10}}\right)
$$

- $\mathrm{L}_{\text {day }}$ is the A-weighted long-term average sound level as defined in ISO 1996-2: 1987 (e.g. ISO [6]), determined over all-the-day periods of a year,

- $\mathrm{L}_{\text {evening }}$ is the A-weighted long-term average sound level as defined in ISO 1996-2: 1987, determined over all-the-evening periods of a year,

- $\mathrm{L}_{\text {night }}$ is the A-weighted long-term average sound level as defined in ISO 1996-2: 1987, determined over all-the-night periods of a year.

In Greece, however, even though the noise indicators $\mathrm{L}_{\text {den }}$ and $\mathrm{L}_{\text {night }}$ are applied and determined by means of European common assessment methods, the relevant limits are yet to be defined. 
Objective measurements of environmental road traffic noise levels are an indispensable and important part of any environmental noise protection program. The index $\mathrm{L}_{\mathrm{A}}$ eq 'Equivalent Continuous Sound Level' is accepted across the globe as the essential averaged parameter - as per the above directive indicators - representing the amount of energy present in the measured, fluctuating sound pressure level. However, additional analysis of statistical distributions of noise levels is a useful tool when assessing environmental noise, as per noise index $\mathrm{L}_{\mathrm{A}} 90$ (the level exceeded for $90 \%$ of the measurement time), when used as an indicator of background noise levels, while $\mathrm{L}_{\mathrm{A}} 10$ (18 h) is also used in Greek noise abatement legislation (level exceeded for $10 \%$ of the measurement time from 06:00 to 24:00 h) to indicate the level of traffic noise events. Therefore, a full monitoring environmental noise program was executed to assess areas along the Elefsina-Korinthos motorway expected to need possible noise mitigation measures, including 24-h acoustic measurement of the existing situation (during operation) of all sections that may require noise barrier implementation. Program execution was completed in accordance with the EU directive 2002/49 (e.g. Directive [4]), which covers the following environmental noise indices:

- $\mathrm{L}_{\mathrm{A}} 10(18 \mathrm{~h})$, according to the existing environmental road noise limits, and $\mathrm{L}_{\mathrm{A}}$ eq(08.00-20.00), according to the existing environmental road noise limits (e.g. JMD 17252 [3])

- $\mathrm{L}_{\mathrm{A}} \mathrm{eq}(24 \mathrm{~h})$

- $\mathrm{L}_{\text {day }}(07.00-19.00)$

- $\mathrm{L}_{\text {evening }}(19.00-23.00)$

- $\mathrm{L}_{\text {night }}(23.00-07.00)$ and

- $\mathrm{L}_{\text {den }}$, according to EU directive (e.g. Directive 2002/49,[4])

In total, some 40 acoustic measurements of 24-h duration each, were executed along the motorway in distinct geographic locations related to receptors in the vicinity of the sections above in distances of $\leq 200 \mathrm{~m}$ from the closest edge of the approved existing town or settlement boundaries and measured from the edge of the road using special automotive road traffic environmental noise monitoring stations (Fig. 3), equipped with statistical noise analyzers and all weather/bird protection microphone, thus, ensuring that full application of all requirements of the EU Directive especially regarding the height measurement of 3,8-4,2 $\mathrm{m}$ was fulfilled.

However, to ensure a complete analysis and evaluation of the existing acoustic environment, along the length of each road section, additional receptors were measured and evaluated enriching
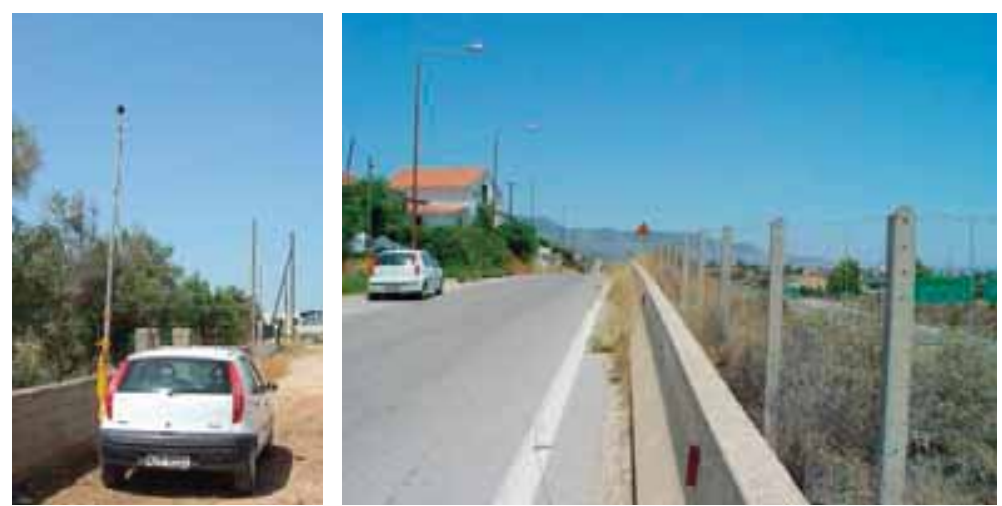

Figure 3: Road traffic noise mobile monitoring station at Elefsina-Korinthos motorway. 
environmental acoustic sensitivity, even though their location was outside the existing town/settlements plan boundaries. The measuring equipment was calibrated (acoustical calibrator) before each acoustic measurement so that the reliability of results was preserved during the measurements and monitoring of the acoustic environment. The execution of measurements was conducted entirely in the absence of rain and strong wind conditions, while for conditions of light wind with a speed of $<2 \mathrm{~m} / \mathrm{s}$, a special wind protector/shield for the microphone was used. Measurements were not conducted in locations where the direct acoustic environment was influenced by other noise sources, that is, neighborhood noise, worksite operation, building construction, etc., or where road traffic was influenced, interrupted, or even disturbed (i.e. accidents, etc.). Finally, calibration of all measuring equipment was necessary to calibrate sound level meters using a suitable acoustical calibrator before and after each series of measurements, at the specific frequency of $1 \mathrm{kHz}$ for a given standard level for each instrument.

The monitoring program ensures:

- the control and enhancement of the measurement setup,

- the identification of road traffic noise sources and relevant flow conditions,

- the avoidance of interference with equipment or measurement,

- a wide dynamic range and efficient data logging with huge storage capacity as well as trigger capabilities and simultaneous measurement of all noise parameters.

The assessment of the hourly fluctuation of all 24-h acoustic measurements executed, together with the road geometric and urban planning data and characteristics of the built-up areas adjacent to the road axis, was the basis of the final noise calculations for the dimensions, density, and type of material for the noise barrier(s) that will potentially be defined as a necessary measure in selected locations. Evaluating the results of all 24-h measurements, as presented in the relevant diagrams for the indexes $\mathrm{L}_{10}(18 \mathrm{~h}), \mathrm{L}_{\text {den }}$ and $\mathrm{L}_{\text {night }}$ (see Fig. 4), it is clear that the immediate implementation of noise barriers of adequate height and length is necessary in several of locations-receptors examined since the relevant recorded levels of noise indices exceed, and significantly on - several occasions - the maximum permissible limits of the $\mathrm{L}_{10}(18 \mathrm{~h})$ noise index (e.g. TT\&E SA, [7])

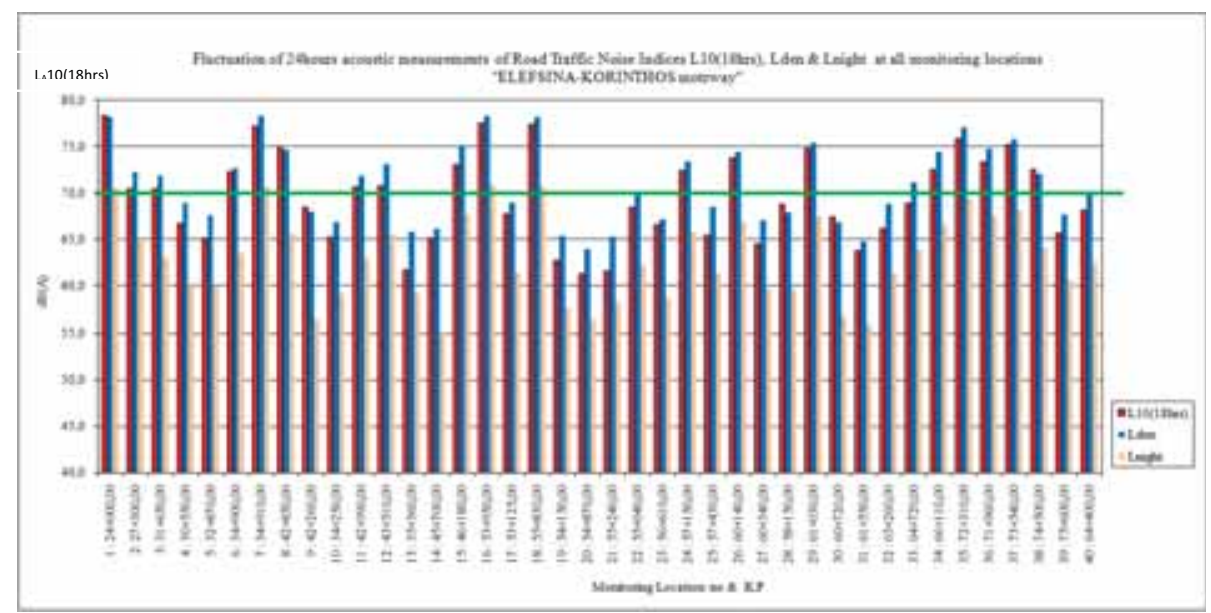

Figure 4: Environmental road traffic noise index $\mathrm{L}_{\mathrm{A}} 10(18 \mathrm{~h})$ fluctuation at all monitoring locations (KP - Kilometric Point) compared to maximum permissible noise level (see green line). 


\subsection{Environmental road traffic vibration monitoring program}

There is a correlation between the way people perceive highway noise and highway traffic-induced vibration (e.g. Watts [8]). With the increase of the ground-borne sound pressure level, the number of people expressing annoyance and complaints about vibration has increased. Airborne noise and vibration caused by the same source, that is, road traffic also interact. The main factors influencing road traffic-induced vibration are presented below. These factors include the source of vibration, the transmission path, and the receiver (e.g. Hein, Hajek, Blaney [9]):

- Source (road traffic): surface condition, traffic flow synthesis and vehicle speed

- Transmission path: receptor's distance, soil/ground absorption, spatial topography

- Receiver: type of Building and Location

The condition of the pavement surface is the most important parameter for ground-borne noise and vibration generation. This is a significant factor that can be controlled by highway agencies, as in this case where extensive upgrade works were undertaken. To evaluate the vibration caused by the road traffic from the operation of Elefsina-Korinthos motorway, an extensive monitoring program was executed measuring vibrations caused by the existing traffic during a typical working day along the motorway and including measurements of vibrations of short duration - one per receiver position (peak particle velocity $-\mathrm{z}$ in $\mathrm{mm} / \mathrm{s}$ ). To ensure the selection of the appropriate receiver/measurement locations, environmental road traffic noise limits were already exceeded, receivers were chosen based on the assumption that these locations already exposed to elevated noise levels were expected to present a higher probability of also exceeding maximum vibration levels. Some 24 receiver/locations were identified along the motorway.

The Greek environmental legal framework does not include vibration or ground-borne noise indices and limits from transportation networks; therefore, the most usual vibration and ground-borne criteria (both indices and limits) for both construction and operation phases are presented in Table 1, which is based on the CHABA Report (e.g. Von Gierke [10], Vogiatzis, Mouzakis [11]):

It should also be noted that in Greece, for the protection of museum exhibits and sensitive archaeological monuments, the limit of $0.2 \mathrm{~mm} / \mathrm{s}$ has been adopted which is significantly lower and therefore stricter than the corresponding limits of DIN 4150 (e.g. structural vibration in buildings [12]), where the peak vibration velocity values for buildings particularly sensitive to vibrations, for the foundation and the overlying floors, are as follows:

- Foundation: for frequencies $<10 \mathrm{~Hz}$ at $3 \mathrm{~mm} / \mathrm{s}$

- Overlying floors: for all frequencies $8 \mathrm{~mm} / \mathrm{s}$

Table 1: Maximum permissible vibration levels suggested in Greece according to 'CHABA Report NTIS AD-A044384' for construction phases of major transportation infrastructure projects.

\begin{tabular}{lll}
\hline \multirow{2}{*}{ Use of building } & \multicolumn{2}{c}{ Suggested vibration limits } \\
\cline { 2 - 3 } Residential and other buildings & Acceleration $\mathrm{rms}^{(1)}$ & Vibration velocity(2) \\
Monuments and Sensitive buildings & $0,5 \mathrm{up}$ to $1 \mathrm{~m} / \mathrm{s}^{2}$ & $13 \mathrm{up}$ to $28 \mathrm{~mm} / \mathrm{s}$ \\
\hline
\end{tabular}

(1) H.E. Von Gierke NTIS Report AD-AO44384 (e.g. Von Gierke [10]).

(2) for frequencies $>10 \mathrm{~Hz}$ vibration velocity in $\mathrm{mm} / \mathrm{s}=28.4 *$ acceleration $\mathrm{rms}\left(\mathrm{m} / \mathrm{s}^{2}\right)$. 
However, it is useful to note that the most severe limit ever enforced in Greece - compared to various international standards for extremely sensitive buildings - was set at $0,16 \mathrm{~mm} / \mathrm{s}$ in order to protect the New Acropolis Museum and the archeological area of 'Kerameikos' during the Athens Metro construction (e.g. Vogiatzis K. [13]). Therefore, based on the above analysis for the present monitoring program, the limits of $0.5 \mathrm{~mm} / \mathrm{s}$ and $0.2 \mathrm{~mm} / \mathrm{s}$ were adopted for residential and archeological receptors, respectively (e.g. Vogiatzis K. [14]).

However, it is also noted that according to the relevant Environmental Impact Assessment (EIA) study provisions, the following criteria for the Peak Particle Velocity (PPV) in the vertical direction, measured in $\mathrm{mm} / \mathrm{s}$ were also suggested:

- $12 \mathrm{~mm} / \mathrm{s}$ at $16.5 \mathrm{~Hz}$

- $15 \mathrm{~mm} / \mathrm{s}$ at $63 \mathrm{~Hz}$

The vertical vibration velocity fluctuation was recorded and analyzed in both time and frequency domain in the 24 respected locations using (Fig. 5):

- sensitive 731 A accelerometers and power supplier systems, the WILCOXON's P31 amplifiers and a TEAC RD-130TE digital recorder. The sensors' sensitivity is $10 \mathrm{~V} / \mathrm{g}$, while the amplifier has $450 \mathrm{~Hz}$ filters,

- a National Instruments frequency analyzer for the analysis of the recorded levels of the vibration velocity (reference: 10-9 m/s) at the frequency breadth from $10 \mathrm{~Hz}$ till $200 \mathrm{~Hz}$,

- a converter from analog to digital and suitable anti-aliasing filters, so that the digitalization of signals could be achieved. The sampling speed was $1 \mathrm{kHz}$,

- FFT and time-domain analysis was executed at the frequency range from 1 to $200 \mathrm{~Hz}$.

From the selected 24 locations, the following most representative receptors analysis is shown in Figs. 6-8. In Figs. 9 and 10, the fluctuation of the PPV in the vertical direction, at all locations is also presented with comparison for all suggested limits above (e.g. TT\&E SA [15]).

Based on the above analysis and the results presented below, it is concluded that all monitored locations at Elefsina-Korinthos motorway present extremely low vibration levels which are, in effect, below the common human sensitivity criterion of $0.08 \mathrm{~mm} / \mathrm{s}$, as well as the environmental limits described above. This is due to a successful upgradation of the circulation areas and the elimination of the irregularities of the former situation before the relevant works. The above results are consistent
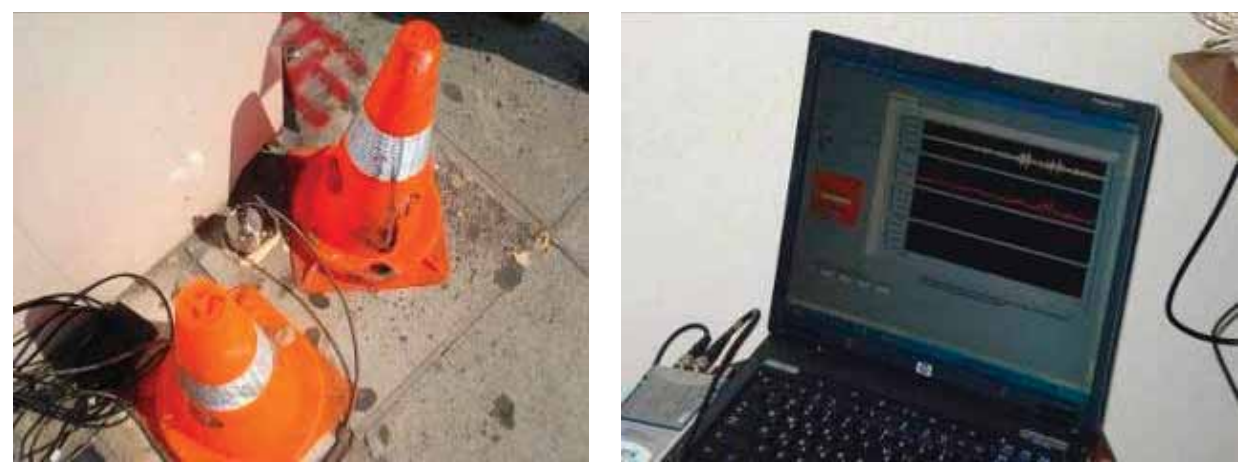

Figure 5: Vibration monitoring measurements setup. 


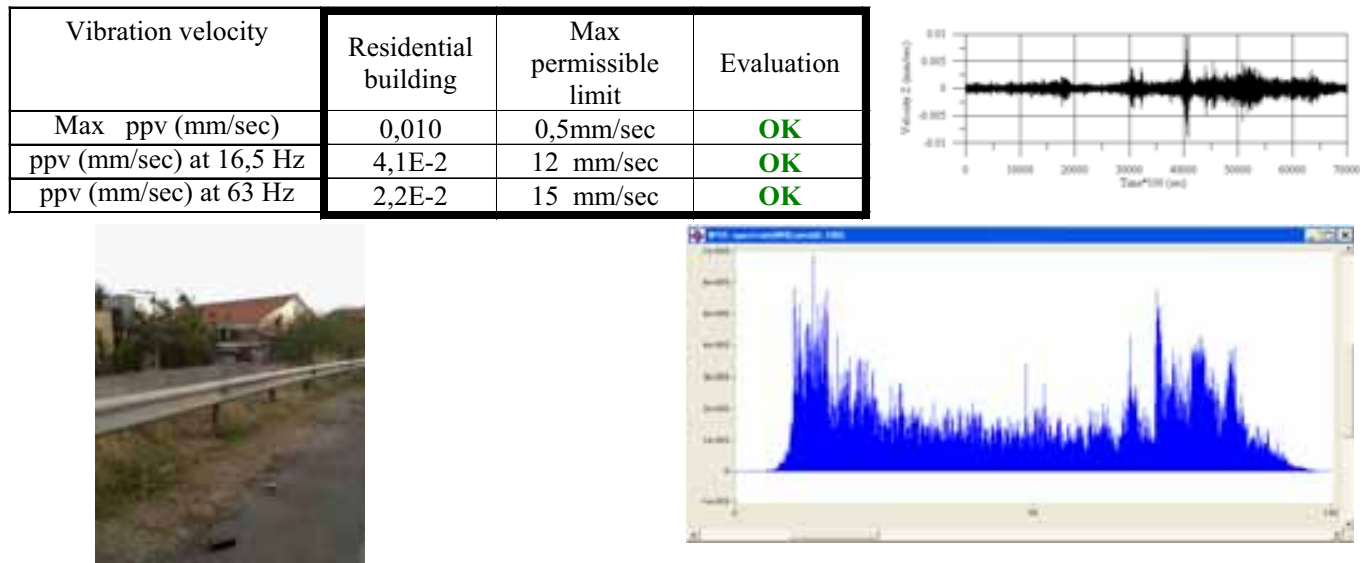

Figure 6: Receptor: Residential use at Km 34 + 900 (FFT and time-domain analysis).

\begin{tabular}{|c|c|c|c|}
\hline Vibration velocity & $\begin{array}{c}\text { Residential } \\
\text { building }\end{array}$ & $\begin{array}{c}\text { Max } \\
\text { permissible } \\
\text { limit }\end{array}$ & Evaluation \\
\hline Max ppv $(\mathrm{mm} / \mathrm{sec})$ & 0,003 & $0,5 \mathrm{~mm} / \mathrm{sec}$ & OK \\
\hline $\mathrm{ppv}(\mathrm{mm} / \mathrm{sec})$ at $16,5 \mathrm{~Hz}$ & $3 \mathrm{E}-2$ & $12 \mathrm{~mm} / \mathrm{sec}$ & OK \\
\hline $\mathrm{ppv}(\mathrm{mm} / \mathrm{sec})$ at $63 \mathrm{~Hz}$ & $1 \mathrm{E}-2$ & $15 \mathrm{~mm} / \mathrm{sec}$ & OK \\
\hline
\end{tabular}
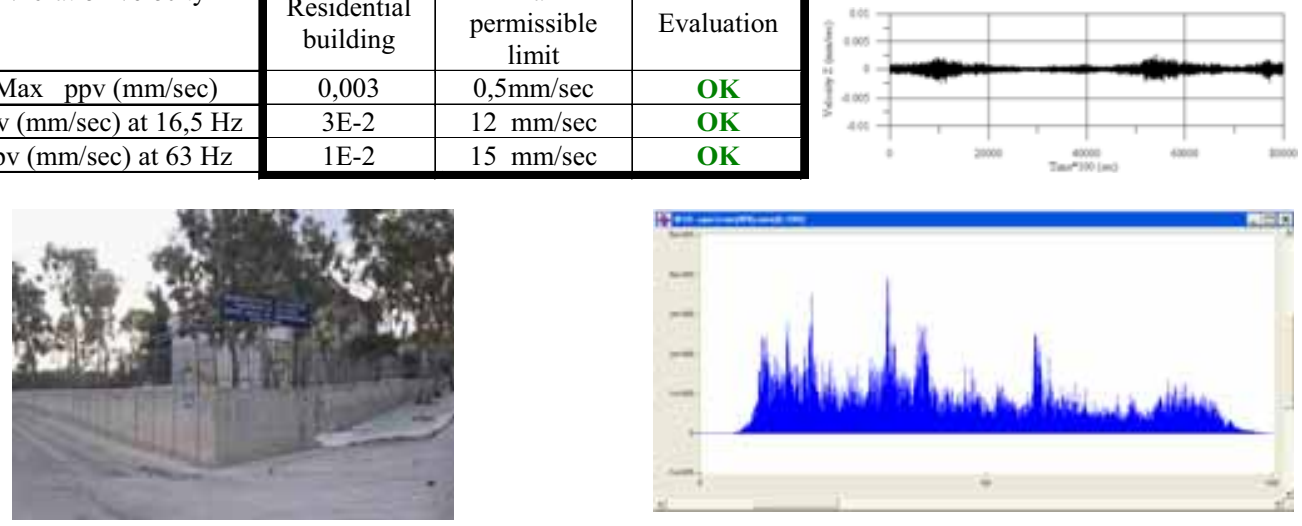

Figure 7: Receptor: Church at Km $46+180$ (FFT and time-domain analysis).

\begin{tabular}{|c|c|c|c|}
\hline Vibration velocity & $\begin{array}{c}\text { Residential } \\
\text { building }\end{array}$ & $\begin{array}{c}\text { Max } \\
\text { permissible } \\
\text { limit }\end{array}$ & Evaluation \\
\hline Max ppv $(\mathrm{mm} / \mathrm{sec})$ & 0,065 & $0,5 \mathrm{~mm} / \mathrm{sec}$ & OK \\
\hline $\mathrm{ppv}(\mathrm{mm} / \mathrm{sec})$ at $16,5 \mathrm{~Hz}$ & $7 \mathrm{E}^{-2}$ & $12 \mathrm{~mm} / \mathrm{sec}$ & OK \\
\hline $\mathrm{ppv}(\mathrm{mm} / \mathrm{sec})$ at $63 \mathrm{~Hz}$ & $1 \mathrm{E}^{-1}$ & $15 \mathrm{~mm} / \mathrm{sec}$ & OK \\
\hline
\end{tabular}
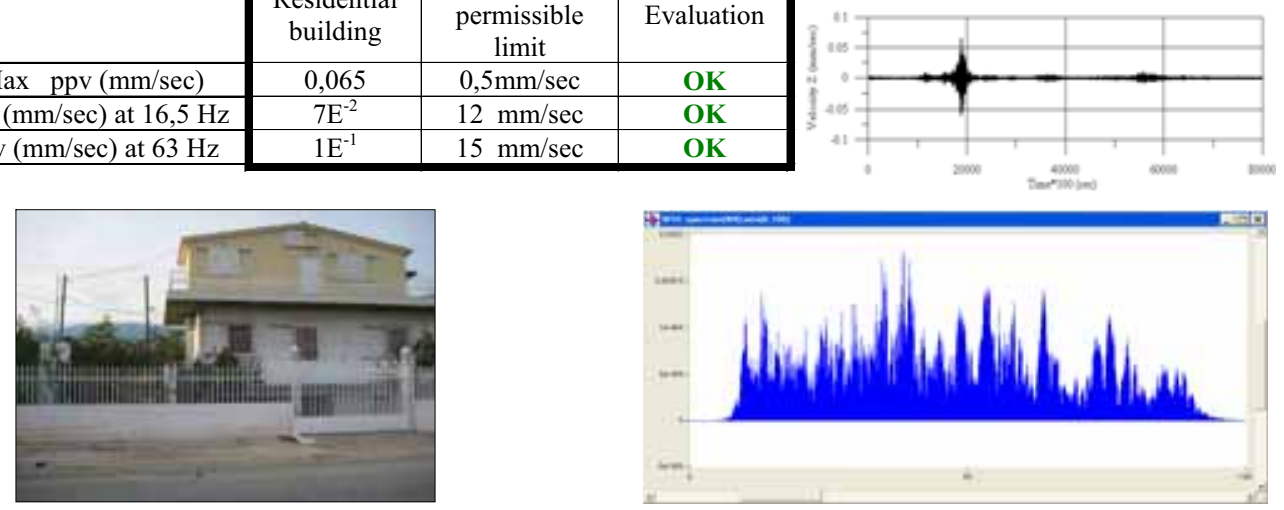

Figure 8: Receptor: Residential use at Km $57+150$ (FFT and time-domain analysis). 


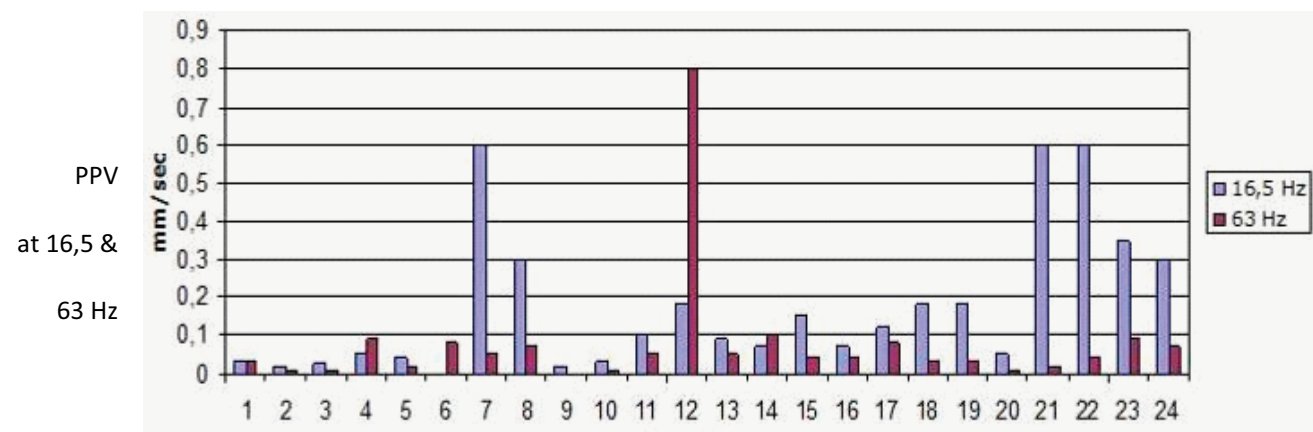

Figure 9: Elefsina-Korinthos motorway, PPV analysis at 16.5 and $63 \mathrm{~Hz}(\mathrm{~mm} / \mathrm{s})$ at all monitoring locations.

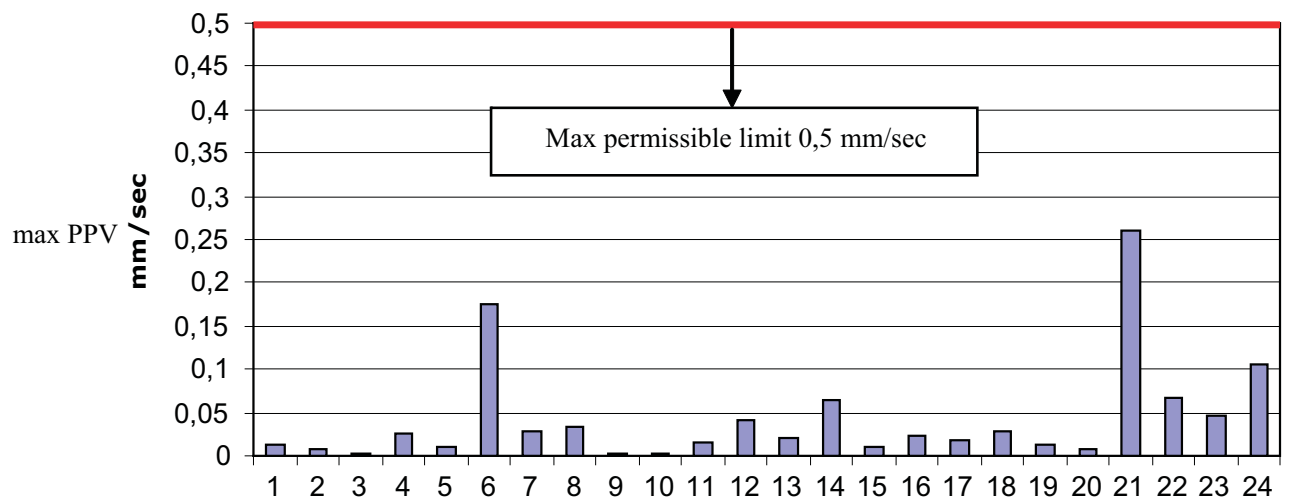

Figure 10: Elefsina-Korinthos Motorway: $\max$ PPV (mm/s) at all monitoring locations.

with previous surveys (e.g. Watts [16]) and were the effect of traffic vibrations in mostly residential areas situated over small distances of roadways carrying trucks. The peak vertical velocity at foundations never exceeded $1.0 \mathrm{~mm} / \mathrm{s}$. These vibration levels could be classified as imperceptible as they are well below the abovementioned levels responsible for minor damage and causing annoyance.

\section{CONCLUSIONS: NOISE ACTION PLAN AND MITIGATION MEASURES}

The above findings of the environmental vibration and ground-borne noise monitoring program, indicate that the condition and the quality of the upper asphalt layers of the motorway (due to the recent upgrade works) and relevant traffic flows, resulted in extremely low levels of vibration and practically no annoyance to the population adjacent to the motorway.

However, as far as the road traffic environmental noise levels resulted from the monitoring program are concerned, it was found imperative to build an adequate analytical environmental road traffic noise prediction model (e.g. TT\&E S.A. [17]) in line with the relevant EU directivels methodologies (e.g. Directive 2002/49, [4]) and a noise action plan to assess introducing the appropriate noise mitigation measures, which in this case was noise barriers. The methodology used in the prediction model is the NMPB-Routes-2008 - Setra, Ref. 0924-1 and Ref. 0924-2 (e.g. SETRA 2009 [18])

An hourly rate analysis of traffic noise as well as speed and synthesis data were taken into account to assess the overall acoustical impact, in combination with the geometric and town planning features of the surrounding area in direct proximity to the motorway. 
The final detailed acoustic and structural design to determine the major technical characteristics, that is, length, height, material and aesthetic form and density for the noise barriers, was recently concluded. Based on the results, the implementation of the immediate mitigation measures of the noise action plan, it proved essential to introduce various acoustically effective heights of $3.5 \mathrm{~m}, 4.0$ $\mathrm{m}$, and $4.5 \mathrm{~m}$. The exact location (start and end kilometer position) and dimensioning of each noise barrier with emphasis on the necessary effective height of each barrier are presented in Table 2 below. The maximum allowed limit of the noise index $\mathrm{L}_{\mathrm{A}} 10(18 \mathrm{~h})=70 \mathrm{~dB}(\mathrm{~A})$ was applied and achieved for all examined receptors under protection. In Fig. 11, a representative noise map and cross section for the environmental road traffic noise levels in an education complex depicting the effectiveness of the proposed noise barrier are presented.

Therefore to protect sensitive land uses from environmental noise, the immediate application of all noise barriers presented below corresponding to the protection of all receptors within the limits of settlements and also to special uses requiring immediate noise protection, for example, churches, was proposed. The main synthetic axes upon which the total aesthetical and acoustic proposal for the necessary barrier form was based are summarized below:

- The need for implementation of acoustic criteria for noise protection;

- minimal possible perturbation residents habits in level of neighborhood, and

- aesthetic consistency of manufacture with the built-up surrounding landscape.

In Fig. 11, some alternative noise barrier aesthetic views are presented as the result of a relevant comparative evaluation to ensure acceptance from the inhabitants in the proximity of the motorway and prevent visual intrusion and visual pollution.

Figure 12, shows a typical mixed barrier with both concrete and semi-transparent Polymethylmaethacrylate (PMMA) panels, as constructed in Elefsina-Korinthos motorway.

It is important to underline the fact that both airborne and ground-borne environmental noise and vibration monitoring networks have proved to be crucial parameters in sustainability assessments of

Table 2: Noise barriers for the protection of all receptors within town boundaries.

\begin{tabular}{llllccc}
\hline \multicolumn{6}{c}{ Elefsina-Korinthos motorway: towards Athens and Korinthos } \\
\hline No & Km start & Km end & Towards: & Length $(\mathrm{m})$ & Barrier height $(\mathrm{m})$ & Barrier surface $\left(\mathrm{m}^{2}\right)$ \\
\hline 1 & $23+564$ & $23+776$ & Korinthos & 212 & 4,5 & 954 \\
2 & $23+584$ & $23+727$ & Athens & 146 & 4,5 & 657 \\
3 & $23+711$ & $23+784$ & Athens & 74 & 4,5 & 333 \\
4 & $24+220$ & $24+410$ & Korinthos & 194 & 4,5 & 873 \\
5 & $32+308$ & $32+406$ & Korinthos & 98 & 4,0 & 392 \\
6 & $32+676$ & $32+814$ & Korinthos & 140 & 4,0 & 560 \\
7 & $33+702$ & $33+805$ & Athens & 104 & 4,5 & 468 \\
$8 *$ & $45+592$ & $45+720$ & Korinthos & 122 & 4,5 & 549 \\
$9 * *$ & $63+343$ & $63+574$ & Athens & 230 & 4,0 & 920 \\
10 & $74+292$ & $74+958$ & Athens & 656 & 4,5 & 658 \\
11 & $75+707$ & $75+911$ & Korinthos & 188 & 3,5 & 9.316 \\
\multicolumn{7}{l}{ TOTAL m $^{2}=$} \\
\hline
\end{tabular}

* Church (sensitive receptor);* Education use (sensitive receptor). 

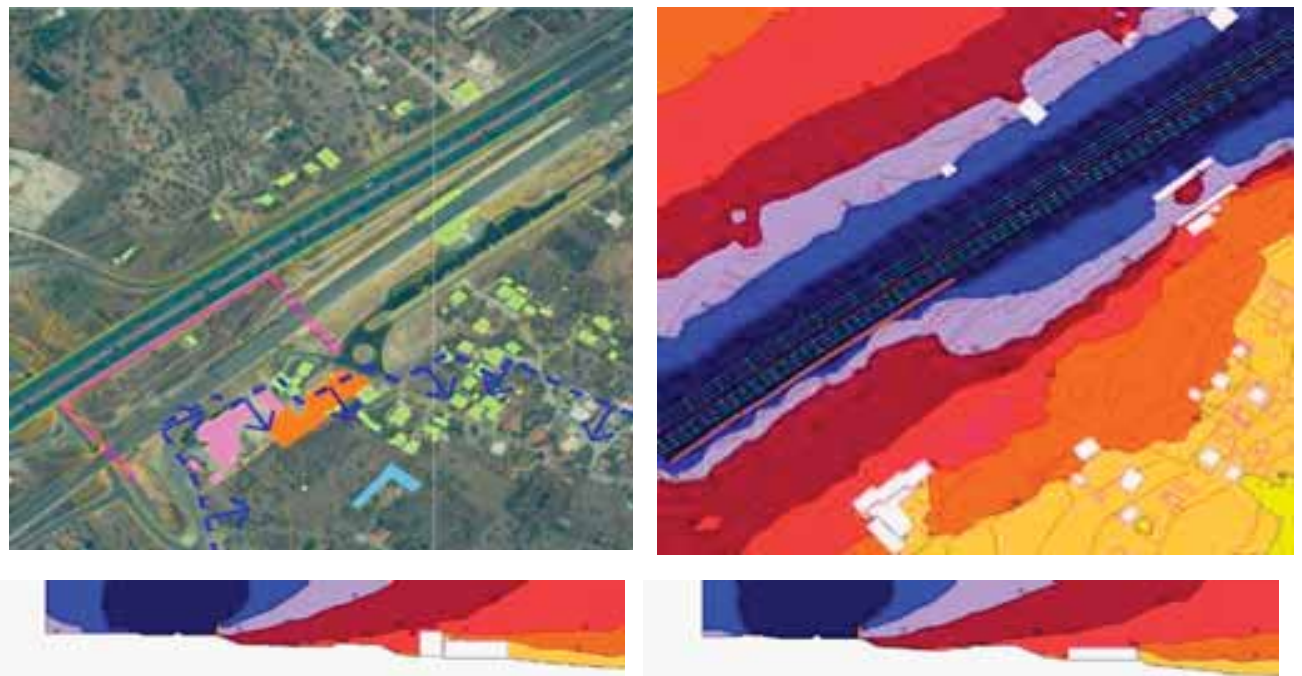
*

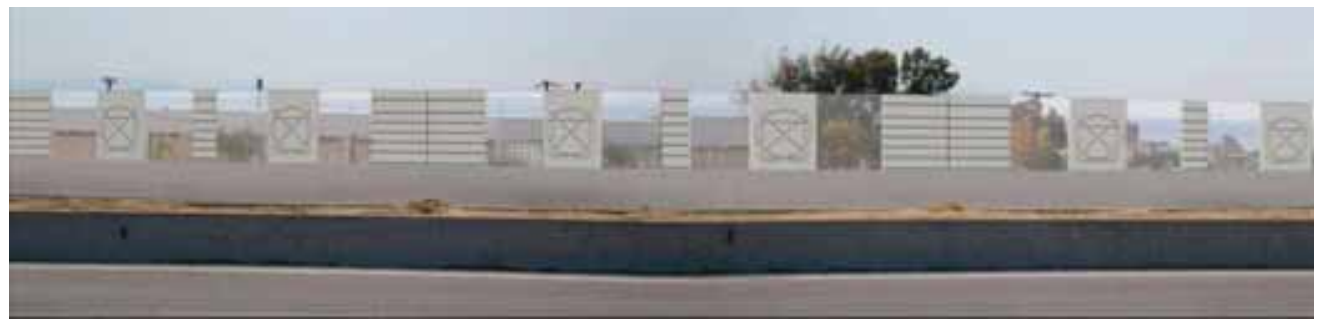

Figure 11: Road traffic noise map and cross sections: effectiveness of the proposed noise barrier and photorealistic adaptation.
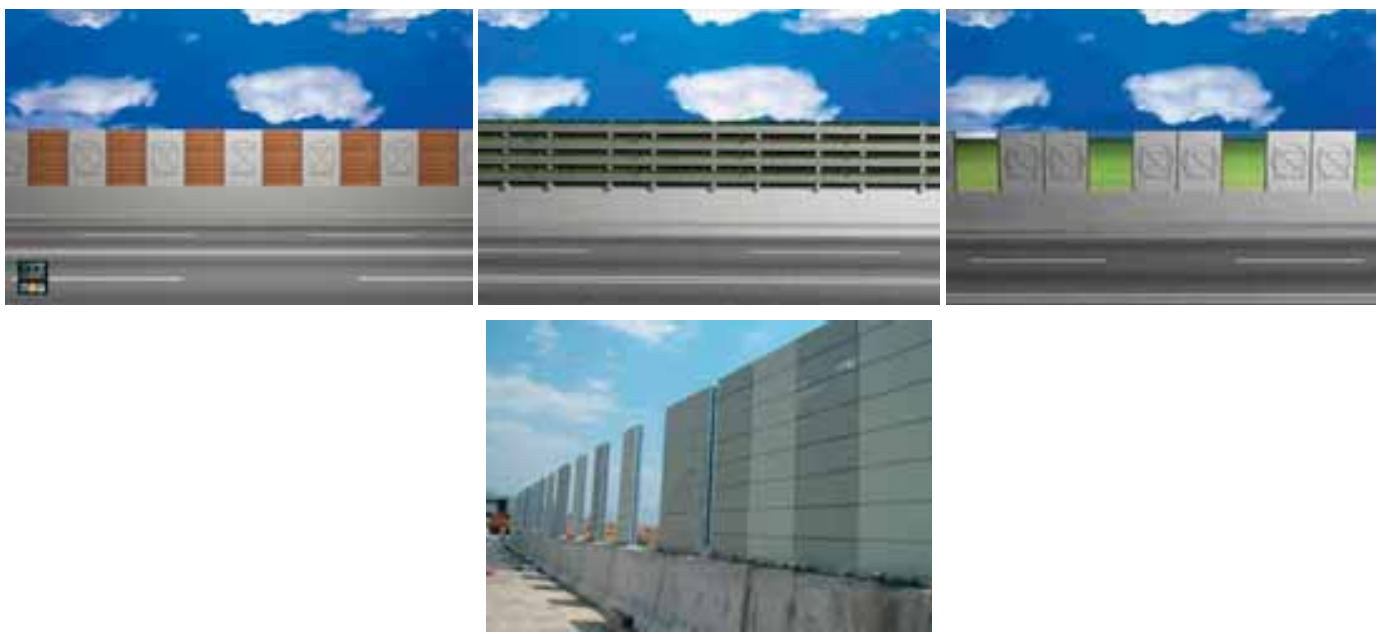

Figure 12: Aesthetic views of some alternative types of noise barriers and a typical barrier under construction. 
inter- and semi-urban road networks when evaluating the quality of the acoustic environment and in the implementation of the appropriate noise action plans and mitigation measures. Often unplanned and extensive use of space, especially in the proximity of residential regions, to accommodate more transportation activities is expected to cause a degradation of the acoustic environment. In simple words, excessive road transportation activities will severely damage the urban environment. Therefore, the immediate introduction of comprehensive acoustic environment sustainability indicators and state-of-the-art monitoring networks are more than ever mandatory.

\section{REFERENCES}

[1] http://www.olympiaodos.gr/EN/index.php?ID=project_overv.

[2] WHO-JRC "Burden of disease from environmental noise-Quantification of healthy life years lost in Europe European Centre for Environment and Health and JRC EU, 2011.

[3] Joint Ministerial Decision 17252/19.6.1992, Determination of indicators and maximum permitted noise limits, that come from circulation of on-road and other transportation works Official Journal of Hellenic Republic 395/B/92.

[4] DIRECTIVE 2002/49/EC OF THE EUROPEAN PARLIAMENT AND OF THE COUNCIL. of 25 June 2002 Relating to the assessment and management of environmental noise Official Journal of the European Communities L 189/12 - 18.7.2002.

[5] Vogiatzis K. Le bruit du a la circulation routiere au centre d'Athenes et aux quartiers peripheriques, Conference I JORNADAS SOBRE RUIDO AMBIENTAL, 1990.

[6] ISO 1996-2: 1987 Acoustics - Description and measurement of environmental noise - Part 2: Acquisition of data pertinent to land use (revised by the ISO 1996-2:2007 Acoustics Description, measurement and assessment of environmental noise - Part 2: Determination of environmental noise levels).

[7] TT\&E S.A., Acoustic Design of Noise Barriers for the existing sections of the concession "Elefsina-Korinthos" and "Patras bypass" Stage 1: Acoustic measurements Ref.: RPT EXS ENV ZXXX TTE F 00001-A, 2009.

[8] Watts, G.R. Vibration Nuisance from Road Traffic - Results of a 50 Site Survey, TRRL Laboratory Report 1119, Transport and Road Research Laboratory, Department of Transport, UK, 1984.

[9] David K. Hein, Jerry J. Hajek, Chris T. Blaney Mitigation of Highway Traffic-Induced Vibration Session on Quiet Pavements: Reducing Noise and Vibration 2006 Annual Conference of the Transportation Association of Canada Charlottetown, Prince Edward Island.

[10] Von Gierke, H.E., Guidelines for Preparing Environmental Impact Statements on Noise, Committee on Hearing, Bioacoustics, and Biomechanics Assembly for Behavioral and Social Sciences (CHABA), Working Group 69, For: National Research Council, NTIS AD A044384, 1977.

[11] Vogiatzis K. \& Mouzakis H Criteria for vibration from railway and light rail transportation projects construction for the protection of buildings and the avoidance of annoyance. Epistimoniko Ktirio, B/1999, pp. 57-59.

[12] Structural Vibration in Buildings, Effects on Structures, DIN 4150: Parts 1-3: 1986.

[13] Vogiatzis K. Noise and Vibration Evaluation of a Floating Slab implementation in the Kerameikos Archaeological area at Athens METRO network, International Congress on Sound and Vibration (ICSV16) Krakow: Poland, 5-9 2009.

[14] Vogiatzis K. "Attiki Odos Vibration Monitoring program from road network operation, Attiki Odos" (TT\&E S.A) 2004-2006. 
[15] TT\&E S.A., Amendment of consultancy Agreement for the Acoustic Design of Noise Barriers for the Existing Sections of the concession project "Elefsina - Korinthos" and "Patras bypass" Deliverable 2: $P M_{2,5}, P M_{10}$ and Vibration measurement, Analysis, Evaluation of results Comparison with Environmental Limits, Conclusions - Suggestions, Ref.: RPT EXS ENV ZXXX TTE F 00019/A, 2009-2010.

[16] Watts, G.R. The Effects of Traffic Induced Vibrations on Heritage Buildings - Further Case Studies, Research Report 207, Transport and Road Research Laboratory, Department of Transport, UK, 1989.

[17] TT\&E S.A., Acoustic Design of Noise Barriers for the existing sections of the concession "Elefsina - Korinthos" and "Patras bypass" Stage 2: Special Acoustic Study - Special Study of Noise Barriers Implementation Ref.: RPT EKX ENV ZXXX TTE F 00003

[18] Prevision du bruit routier - Setra, Ref. 0924-1 (1 - Calcul des emission sonores dues au trafic routier), \& Ref. 0924-2 (2 - Methode de calcul de propagation du bruit incluant les effets meteorologiques (NMPB 2008)), June 2009. 